\title{
Linking Green Space to Neighborhood Social Capital in Older Adults: The Role of Perceived Safety
}

\author{
Hong, Andy ${ }^{a^{*}}$, Sallis, James F. ${ }^{b}$, King, Abby C. ${ }^{c}$, Conway, Terry L. ${ }^{b}$, Saelens, Brian ${ }^{\mathrm{d}}$, \\ Cain, Kelli L. ${ }^{b}$, Fox, Eric H. ${ }^{\text {e }}$, Frank, Lawrence D. ${ }^{a}$
}

\begin{abstract}
This study examines the moderating effect of perceived safety on the association of green space with neighborhood social capital in older adults. Green space may play an important role for promoting neighborhood social capital and health for older adults; however, safety remains a significant challenge in maximizing the benefits of green space. Data were drawn from 647 independent-living seniors who participated in the Senior Neighborhood Quality of Life Study in the Seattle/King County and Baltimore/Washington DC region. The results suggest that certain green space elements, such as natural sights, may be beneficial to neighborhood social capital of older adults. However, other types of green space, such as parks and street trees, may be less advantageous to older adults who perceive their neighborhoods as unsafe for pedestrians. Findings highlight the importance of pedestrian safety in examining associations of green space with neighborhood social capital in older adults. Further studies using a longitudinal design are warranted to confirm the causality of the findings.
\end{abstract}

\section{Highlights}

- Little is known about the role of safety in linking green space to social capital

- Different types of green space had different effects on social capital

- Natural sights were positively related to social capital regardless of safety

- Street trees and park access were negatively related when people feel less safe

\section{Keywords:}

Green space; Social capital; Social cohesion; Neighborhood; Safety; Older adults; Seattle; Baltimore

\footnotetext{
a School of Population and Public Health, Faculty of Medicine, University of British Columbia, BC, Canada; ${ }^{\mathrm{b}}$ Department of Family and Preventive Medicine, University of California, San Diego, CA, United States; ${ }^{\mathrm{c}}$ Division of Epidemiology, Department of Health Research \& Policy, Stanford University, CA, United States; ${ }^{d}$ Seattle Children's Research Institute and

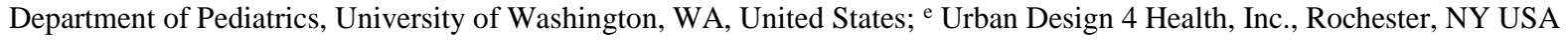

* Corresponding author: Andy Hong (andyhong@gmail.com)
} 
This paper was accepted by Social Science and Medicine. This is an author accepted version.

\section{INTRODUCTION}

Social capital has emerged as an important concept of healthy aging. Although many

3 definitions of social capital exist (Moore and Kawachi, 2017), health researchers have paid

4 particular attention to neighborhood social capital (Kawachi et al., 1999; Kawachi and Berkman,

5 2003; Ziersch et al., 2005). A growing body of research indicates that neighborhood social

6 capital, defined as social resources inherent within community networks, is relevant to the

7 formation of trust, social norms, reciprocity, and mutual support among older people (Agampodi

8 et al., 2015; Berkman and Kawachi, 2000; Cramm et al., 2013; Forrest and Kearns, 2001). With

9 a rise in older adults living alone, collective features of social structures that facilitate social

10 cohesion and interaction are especially important for older adults to gain access to appropriate

11 services and support (Bedney et al., 2010) and maintain an independent and healthy life (Pollack

12 and von dem Knesebeck, 2004; Sirven and Debrand, 2008). However, older adults are more

13 likely to experience shrinking social capital and networks in their community (Glass and Balfour,

14 2003) due to deteriorating physical and cognitive ability that often leads to functional limitation

15 and mobility decline (Metz, 2000).

16 Green space may play an important role for improving older adults' social capital and

17 related health outcomes (Frank et al., 2010a; Michael et al., 2006). Exposure to green space has

18 been shown to promote healthy behaviors, such as walking, cycling, and community gardening

19 (Gebel et al., 2011; Gong et al., 2014). Access to public parks near the home has been associated

20 with higher levels of walking and physical activity (Frank et al., 2007; Giles-Corti et al., 2005)

21 Mounting evidence suggests that green space contributes to mental health through providing

22 social support, and reducing mental stress and fatigue (Frumkin, 2001; Groenewegen et al.,

23 2006; Hartig et al., 2014; Yen et al., 2009). Parks and green space provide shared locations for 
This paper was accepted by Social Science and Medicine. This is an author accepted version.

24 community interaction (Maas et al., 2009b), increase levels of social support (Seaman et al.,

25 2010), and promote engagement in socially oriented activities (Kingsley and Townsend, 2006).

26 A small but growing number of studies have found similar benefits in older adults, suggesting

27 that green space may provide a healthy place for seniors to convene and retain social cohesion, in

28 addition to enhancing their mental health and emotional wellbeing (Coley et al., 1997; Kweon et

29 al., 1998; Maas et al., 2009a).

30 Despite the growing interests in green space, various factors related to safety, such as

31 crime and traffic hazards, may impede access to green space (Weiss et al., 2011) and reduce

32 physical activity among older adults in public outdoor spaces (Mowen et al., 2007). A number of

33 studies have shown that perception of neighborhood safety is associated with the likelihood that

34 residents will participate and interact with their neighbors (Baum et al., 2009; Lindquist and

35 Duke, 1982; Young et al., 2004). In addition to perceptions of crime influencing the desire to

36 walk, the presence of nuisance or unattended dogs (Brownson et al., 2001; Garrett et al., 2012;

37 King et al., 2000; Sallis et al., 1997) lack of adequate lighting (Adams et al., 2009; Troped et al.,

38 2003) and perceived safety walking during the day and at night (Cerin et al., 2009; Giles-Corti,

39 2002) have also been found to be associated with reduced physical activity.

Although perceived safety can be enhanced through improvement in neighborhood

41 environments (Austin et al., 2002), certain green space elements, such as parks and dense

42 vegetation, are associated with increased fear of crime (Jansson et al., 2013; Maruthaveeran and

43 van den Bosh, 2015) and crime activities (Groff and McCord, 2012; Tower and Groff, 2016) in

44 urban environments. Because older people are more likely to express concerns about safety and

45 crime (Lindquist and Duke, 1982), safety remains a significant challenge in maximizing the 
This paper was accepted by Social Science and Medicine. This is an author accepted version.

46 benefits of green space for older adults. Older adults' access to and use of green space may thus

47 be restricted by their perception of safety in the neighborhood (Cho et al., 2005; King, 2008).

To our knowledge, few studies have examined the extent to which older adults'

49 perception of safety may influence the observed relationship between green space and

50 neighborhood social capital. Therefore, the goal of this study is to investigate whether

51 perceptions of traffic, pedestrian, and personal safety moderate the associations of green space

52 with neighborhood social capital in older adults. It is hypothesized that older adults with greater

53 access to green space report increased social capital, after adjusting for socio-demographic

54 characteristics. It is also hypothesized that older adults with greater safety concerns report lower

55 levels of social capital than would otherwise be predicted based on their green space access.

\section{METHODS}

\section{Study design}

This investigation used cross-sectional data from the Senior Neighborhood Quality of

61 Life Study (SNQLS), conducted in the Seattle-King County region of Washington State and the

62 Baltimore-Washington DC region in Maryland. SNQLS aimed to investigate the relationships

63 between the built environment and older adults' health and wellbeing outcomes. Detailed study

64 design and sampling methods are described elsewhere (King et al., 2011). In brief, data

65 collection for the study occurred between 2005 and 2008 and comprised participant recruitment

66 and multiple primary data acquisitions over the course of a full year within each region so that

67 seasonal variation could be considered. Eligible seniors (aged $>65$ years) were recruited from

68216 Census block groups (Seattle- King County $=116$; Baltimore-Washington DC region $=$ 
This paper was accepted by Social Science and Medicine. This is an author accepted version.

69 100), differing in median household income and neighborhood walkability characteristics.

70 Number of participants per block group ranged from 1 to 22, with a median of two. Walkability

71 and income characteristics of each block group were crossed to create four distinct quadrants:

72 higher walkable/higher income, higher walkable/lower income, lower walkable/higher income,

73 and lower walkable/lower income (Frank et al., 2010b; Sallis et al., 2009). Block groups in each

74 quadrant met both income and walkability criteria for that quadrant to obtain a representative

75 pooled sample across the two study regions.

\section{Participant recruitment and assessment procedures}

A total of 3,359 participants were initially contacted by mail and telephone, and were

79 invited to participate in the study. Individuals were eligible to participate if they were aged 65

80 years and over, able to complete the survey in English, and able to walk more than 10 feet at a

81 time. Initial telephone screening interview in person ascertained that study participants had

82 sufficient cognitive ability to complete the survey by mail, online, or via telephone interview.

83 The final sample consisted of 647 participants, excluding 205 participants who lived in

84 retirement communities or assisted living facilities. The reasons for our focus on community-

85 dwelling older adults were two folds: 1) reported difference in perceptions of neighborhood

86 resources between community-dwelling older adults vs. older adults in retirement communities

87 or assisted living conditions (Cho et al., 2012); and 2) the growing interest in policy-relevant

88 research regarding aging in place, i.e. older adults who wish to remain independent in their

89 current residence. Survey response rate (participants/eligible contacts) was $19.3 \%$ overall $(\mathrm{n}=$

90647 , Seattle $=319 ;$ Baltimore regions $=328)$ and did not differ significantly by region. Also, the 
This paper was accepted by Social Science and Medicine. This is an author accepted version.

91 demographic characteristics between the initial recruitment and the final sample did not differ

92 significantly.

93 In terms of sample representation, King et al. (2011) reported comparisons of the SNQLS

94 participants with 2000 Census regional characteristics on available key demographic variables

95 including age, education and ethnicity. Age and education of study participants were comparable

96 to 2000 Census distributions within each region. In the Baltimore region, the percentage of

97 white/non-white participants was comparable to Census data; however, in the Seattle region

98 white participants were slightly over-represented. Institutional Review Boards at the

99 participating academic institutions approved the study, and participants provided written

100 informed consent before participating.

101

102 Measures

$103 \quad$ Neighborhood social capital

104 For the purpose of this investigation, neighborhood social capital was defined using two

105 constructs: social cohesion and social interaction. Social cohesion captures an individual's

106 perception of how closely connected he or she feels with neighbors. Social interaction captures

107 the presence of informal contacts within the neighborhood. Taken together, these constructs

108 represent attitudinal and behavioral dimensions of neighborhood social environment.

109 Social cohesion was defined using the mean of five survey items adapted from Sampson

110 et al. (1997). Participants were asked how strongly they agreed with the following statements: 1)

111 People around my neighborhood are willing to help their neighbors; 2) This is a close-knit

112 neighborhood; 3) People in this neighborhood can be trusted; 4) People in this neighborhood

113 generally don't get along with each other; and 5) People in this neighborhood do not share the 
This paper was accepted by Social Science and Medicine. This is an author accepted version.

114 same values. Each item was rated using a five-point scale from strongly dissatisfied (1) to

115 strongly satisfied (5) on a scale developed by the investigators, and the last two items were 116 reverse coded to match the scale order of other survey items.

117 Social interaction was measured using three survey items adapted from Parker et al.

118 (2001). The original instrument included nine items asking on how many days in the past month

119 the respondent has performed various activities with a neighbor. The present study used the first

120 three items to represent the construct of social greetings. The respondents were asked on how

121 many days in the past month they interacted with their neighbors on the following items: 1)

122 Waved to a neighbor; 2) Said hello to a neighbor; and 3) Stopped and talked with a neighbor.

123 These items were averaged to create a measure of social interaction with their neighbors.

125 Exposure to green space

126 Green space exposure was captured by both objective and perceived measures. The

127 objective green space measure was distance (meters) to the nearest park of any size from

128 participants' home address. Park data were assembled from regional, county and municipal

129 geographic information system (GIS) portals of each study region (Seattle and Baltimore). ESRI

130 ArcGIS version 10.0 (ESRI, Redlands, CA) was used to compute the network distance to the

131 nearest park access point. Network distance was calculated using a walkable road network with

132 limited access highways and ramp segments excluded along which pedestrians could traverse

133 (Frank et al., 2017). Park access points were established at 100 feet fixed intervals at park

134 polygon boundaries and snapped to the walkable road network.

135 The perceived green space measures were derived from two items on the Neighborhood

136 Environment Walkability Scale (NEWS) (Cerin et al., 2009; Adams et al., 2009). Specifically, 
This paper was accepted by Social Science and Medicine. This is an author accepted version.

137 presence of street trees was measured by asking the respondents on a four-point scale how

138 strongly they agreed that there are many trees along the streets in their neighborhood. Presence

139 of natural sights was assessed by asking how strongly the respondents agreed there are many

140 attractive natural sights in their neighborhood (such as landscaping and views). Each item was

141 rated using a four-point scale from strongly agree (1) to strongly disagree (4).

143 Perceived safety measures

144 Safety perception was measured using the four-point scale items corresponding to traffic,

145 pedestrian, and personal safety from the Neighborhood Environment Walkability Scale (NEWS).

146 Traffic safety was assessed by aggregating survey items: perceived traffic volume and speed, and

147 instances of drivers exceeding the speed limits. Pedestrian safety was measured by taking the

148 mean of seven items: presence of pedestrians and bicyclists, pedestrian signal times, crosswalk

149 design, intersection design, presence of busy streets, instances of cars going across sidewalks,

150 and sidewalk ramp design. Personal safety was assessed by aggregating seven items: perceived

151 crime rate, perceptions of safety for walking during the day and at night, presence of loose dogs,

152 perceptions of unsafe alleys, presence of intimidating people hanging out on the street, and

153 presence of streetlights. Previous studies (Cerin et al., 2009, 2006; Saelens et al., 2003) have

154 reported good test-retest reliability and construct validity of the NEWS measures, including

155 perceptions about neighborhood pedestrian and traffic safety, as well as crime safety.

157 Covariates

158 Socio-demographic characteristics included as covariates were: age, sex, education, 159 household income, ethnicity, and marital status. Education was measured on a five-point scale 
This paper was accepted by Social Science and Medicine. This is an author accepted version.

160

161

162

163

164

165

166

167

168

169

170

171

172

173

174

175

176

177

178 proportion for categorical variables - site $=$ Baltimore, age $=$ average age (74.18), sex $=$ female, 182 marital status $=$ married , income $=\$ 20 \mathrm{k}-\$ 40 \mathrm{k}$, education $=$ some college, home ownership $=$

ranging from 1 ( $\leq$ high school diploma) to 4 ( $\geq$ graduate degree). Household income was grouped into four levels, ranging from $1(<\$ 20,000)$ to $4(\geq \$ 70,000)$. A dummy category was added to handle 48 missing household income data, and the model results remained the same with or without the missing dummy. Hence, the results with the missing dummy were reported. Ethnicity was coded as a dummy variable indicating whether the respondents were white or nonwhite (including Hispanic). Also included were home ownership, years of living in the current residence, and self-rated health. Self-rated health was assessed using the item "In general, would you say your health is" to which respondents indicated their answer on a five-point scale $(1=$ Poor to $5=$ Excellent $)$.

\section{Analytical approach}

Given the nature of the data using a stratified sampling design, a multilevel model using block groups as a random effect cluster variable was used to account for the hierarchical structure with individuals nested within block groups. To examine perceived safety as a moderator of the relationship between green space and neighborhood social capital; the models were estimated for each outcome variable (social cohesion and social interaction) that included the green space variables, perceived safety variables, and their interactions. For interpretation, variables entered into the interaction term were centered at the mean of the distribution.

Based on the model results, significant interactions were plotted with predicted social cohesion and social interaction on the y-axis. The interaction effects were plotted by holding covariates constant with mean values for continuous variables or values with the highest 
This paper was accepted by Social Science and Medicine. This is an author accepted version.

183 owner, years of residence $=$ average years of residence (25.05), health $=$ average health status

184 (3.47). The plots showed the effects of the green space quartiles (1 through 4) for different levels

185 of safety (1 standard deviation above ("high") and below ("low") the mean), while holding all

186 the other covariates constant. All analyses were conducted using $\mathrm{R}$ version 3.3.2 ( $\mathrm{R}$

187 Development Core Team, 2014). The multilevel models were fitted using lmer function from the

188 lme4 package, and the interaction plots were created using effect function from the effects

189 package.

190

191

192 RESULTS

193 Table 1 provides a descriptive summary of the sample demographics. Respondents had 194 an average age of 74.2 years (range $=66-97$ years, SD 6.2), were well balanced by sex (women $195=52 \%)$, and were married or living with partner in more than half of the cases (58\%). About

$19679 \%$ of the respondents had at least some college education, and more than half had household

197 incomes greater than $\$ 40,000$. The majority of the respondents were white $(71 \%)$ and

198 homeowners (85\%). The average duration at their current residence was 25.1 years (SD 15.4),

199 and the average response of self-rated health was 3.5 (SD 0.9), indicating that their health was

200 generally good.

201

202

203

INSERT TABLE 1 ABOUT HERE

204

205 
This paper was accepted by Social Science and Medicine. This is an author accepted version.

223 social interaction $(p>0.6)$.

\section{Main effects of green space}

Main effects of perceived safety

Among the three green space measures, presence of natural sights had the strongest association with social cohesion $(\mathrm{B}=0.13, p \leq 0.01$, Table 2$)$ and social interaction $(\mathrm{B}=1.16 \sim$ $1.23, p \leq 0.01$, Table 3). Presence of street trees was not significantly related to social cohesion but was marginally related to social interaction ( $\mathrm{B}=0.66 \sim 0.79, p \leq 0.10$, Table 3 ). Park access was not significantly related to either social cohesion or social interaction in the main effect.

\section{INSERT TABLE 2 ABOUT HERE}

There were positive and significant associations of pedestrian safety with social cohesion $(\mathrm{B}=0.22, p \leq 0.01$, Table 2$)$ and social interaction $(\mathrm{B}=2.02 \sim 2.20, p \leq 0.05$, Table 3$)$. Traffic safety was not significantly related to social cohesion but was marginally and inversely related to social interaction $(\mathrm{B}=-0.91 \sim 1.02, p \leq 0.10$, Table 3$)$. Personal safety was significantly and positively related to social cohesion ( $\mathrm{B}=0.24 \sim 0.26, p \leq 0.01$, Table 2 ) but less important for 
This paper was accepted by Social Science and Medicine. This is an author accepted version.

(1)

(1)

2

\section{Interactions between green space and pedestrian safety}

Regarding the interaction effects, no statistically significant interaction effects were found between natural sights and perceived pedestrian safety. Although not statistically significant, the effect of natural sights appears to be greater in magnitude for neighborhood with lower safety perception than the one with higher safety perception. The interaction between pedestrian safety and street trees was significant for the social cohesion measure $(\mathrm{B}=0.17$ $0.19, p \leq 0.05$, Table 2). Similarly, the interaction between pedestrian safety and park access was significant for the social interaction measure $(\mathrm{B}=-0.003, p \leq 0.05$, Table 3 ), suggesting that the impact of park access may depend on perception of pedestrian safety. Figure 1 depicts these significant interaction effects, showing the moderating role of pedestrian safety on the association of street trees and park access with neighborhood social capital.

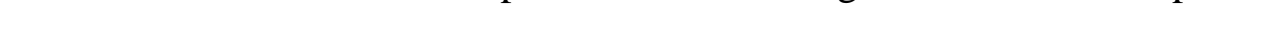

\section{INSERT FIGURE 1 ABOUT HERE}

\section{DISCUSSION}

This paper presents findings that contribute to our understanding of the relationship between green space, perceived safety, and neighborhood social capital in older adults. The results generally supported our research hypotheses, with some exceptions and unexpected findings. Greater presence of natural sights was associated with greater social capital, suggesting a protective effect of natural sights on neighborhood social capital. On the other hand, presence of street trees and park access was positively related to neighborhood social capital only for 
This paper was accepted by Social Science and Medicine. This is an author accepted version.

252 participants who rated their neighborhoods as safe for pedestrians; but negatively related to

253 neighborhood social capital for those who perceived their neighborhoods as less safe. These

254 results suggest that pedestrian safety may moderate the effect of green space on neighborhood

255 social capital in older adults, depending on the types of green space available.

256 In terms of the green space main effects, presence of natural sights had the strongest

257 relation to neighborhood social capital. This result is consistent with previous studies that

258 reported positive associations of neighborhood physical elements with social capital and mental

259 health outcomes of older adults (Sugiyama et al., 2008; Yen et al., 2009). Natural sights include

260 a variety of neighborhood amenities, such as landscape elements and design, which may

261 represent neighborhood cleanliness and orderliness. Previous studies have shown that

262 neighborhood amenities, such as lighting, public facilities, and sidewalk and curb conditions, can

263 shape walking behavior of older adults (Mendes de Leon et al., 2009) and promote neighborhood

264 safety and social cohesion (Van Dijk et al., 2014). Well-maintained natural sights may be an

265 indicator of neighborhood wealth as well as neighborhood upkeep and maintenance, which has

266 been correlated with increased levels of perceived safety (Austin et al., 2002) and higher social

267 capital (Wood et al., 2008). Taken together, the results suggest that attractive natural sights in

268 neighborhood, such as landscaping elements, neighborhood aesthetics, and neighborhood

269 upkeep, may synergistically interact with safety perceptions to influence neighborhood social

270 capital among older adults.

271 Regarding the safety main effects, only perception of pedestrian safety was important for

272 neighborhood social capital among older adults. Interestingly, other measures of safety did not

273 show consistent main effects. As noted by one prior study (Bracy et al., 2014), the consistent

274 main effects of pedestrian safety may be due to the fact that this measure captures the perception 
This paper was accepted by Social Science and Medicine. This is an author accepted version.

275 of the built environment more precisely (e.g. design of crosswalks and quality of sidewalks), as

276 opposed to other two measures that may be capturing safety concerns somewhat loosely. Further

277 investigation into the accuracy of different types of measures in describing safety perception

278 would be fruitful.

279 Nonetheless, the consistent and significant main effects of pedestrian safety suggest that a

280 pedestrian-friendly environment may be one of the more important factors in promoting

281 neighborhood social capital. This result is consistent with a growing body of research on the

282 relationships between neighborhood characteristics, safety, and health (De Jesus et al., 2010;

283 Kruger et al., 2007; Ruijsbroek et al., 2016; Sampson, 2003; Young et al., 2004; Ziersch et al.,

284 2005). A qualitative study of Australian adults found that unsafe destinations in low-income

285 neighborhoods were seen as detrimental to social capital (Baum and Palmer, 2002). Another

286 study suggested that people who rated greater perception of pedestrian comfort and safety were

287 more likely to have greater sense of community (Lund, 2002). Our results extend prior findings

288 by suggesting that perceived safety with regard to pedestrian environment may have an

289 independent association with older adults' social capital, regardless of surrounding green space.

290 In contrast with the consistent positive associations of natural sights, street trees and park

291 access showed mixed results depending on the seniors' perception of pedestrian safety (Figure

292 1). In neighborhoods perceived as having high pedestrian safety, greater presence of street trees

293 and park access were associated with greater neighborhood social capital. However, greater

294 presence of street trees and park access were associated with lower neighborhood social capital

295 among older adults who rated their neighborhoods as less safe for pedestrians.

296 Although few studies have directly examined the negative aspects of green space on

297 social capital, the mechanism that links trees and parks with fear and safety has been extensively 
This paper was accepted by Social Science and Medicine. This is an author accepted version.

explored in criminology and sociology literature (Sullivan et al., 2004; Troy et al., 2012; Wolfe and Mennis, 2012). Trees, or more broadly urban vegetation, have long been recognized as a crime generator because of its possibility to offer places to hide criminal behaviors (Nasar et al., 1993). In high crime neighborhoods, dense vegetation has been correlated with increased fears among residents in the surrounding neighborhoods (Shaffer and Anderson, 1985). Urban parks have also been positively associated with fear of crime (Maruthaveeran and van den Bosh, 2015) and actual crime activities (Groff and McCord, 2012; Tower and Groff, 2016), diminishing the role of green space as providing opportunities for social gatherings and activities. Our results resonate with findings from criminology and sociology literature in that, when older adults feel less safe in their neighborhood, street trees and parks may work against bridging social capital. Given that older people generally have greater safety concern (Clememte and Kleiman, 1976), pedestrian safety may play a larger role in making neighborhoods either desirable or undesirable for social gathering, providing important implications for urban green space design to maximize surveillance to support planning for age-friendly communities.

The present study offers more nuanced understanding of the role that safety plays in linking green space to neighborhood social capital. Some of the limitations included crosssectional data, which limited our ability to make any causal inferences. It is possible that greater social capital may have contributed to more investment in green space and greater feelings of safety (Ziersch et al., 2005). Further studies using a longitudinal design may help to confirm the existence and direction of causality, and conducting similar studies in different geographical contexts may increase the generalizability of findings. In terms of the analysis, the two outcome measures (social cohesion and social interaction) were fitted separately; however, it would be useful to develop a multivariate mixed-effects model, given the correlated structure of the 
This paper was accepted by Social Science and Medicine. This is an author accepted version.

321 outcome measures $(\mathrm{R}=0.27, p<0.01)$. The present study relied on a subjective rating of safety,

322 which in some studies has been related to affect health outcomes more strongly than objective

323 crime rates (Lovasi et al., 2014). However, additional analysis using actual crime data may be

324 useful to uncover other aspects of safety (e.g. incivilities) in explaining the observed relationship.

325 Lastly, this study captured neighborhood greenness more holistically by using both objective and

326 perceived measures. However, it would be fruitful to incorporate other measures of green space,

327 for example, greenness measure derived from satellite imageries, such as normalized difference

328 vegetation index (NDVI).

CONCLUSION

This study provides evidence that perception of pedestrian safety may moderate the 332 impact of green space on neighborhood social capital in older adults. The results suggest that

333 certain neighborhood green space element, such as attractive natural sights, is positively related

334 to older adults' social capital. However, other types of green space, such as parks and street trees, 335 may have an undesirable impact on neighborhood social capital among older adults who view

336 their neighborhood as less safe. If these results are confirmed by prospective studies, they could

337 have implications for the planning and design of green space for older adults. Access to

338 appropriate green space may reflect one of a constellation of elements that could help to address

339 the unique needs of older adults who wish to age in place but have concerns for their

340 neighborhood safety. 
This paper was accepted by Social Science and Medicine. This is an author accepted version.

344

345

346

347

348

349

350

351

352

353

354

355

356

357

358

359

360

361

362

363

364

365

366

367

368

369

370

371

372

373

374

375

376

377

378

379

380

\section{Conflict of interest}

The authors do not have conflicts of interest to declare.

\section{Acknowledgements}

The funding of the data used in this study was provided by grant HL67350 from the National

Heart, Lung, and Blood Institute. The sponsor was not involved in any part of study preparation,

execution, analysis, and preparation of the manuscript.

\section{REFERENCES}

Adams, M.A., Ryan, S., Kerr, J., Sallis, J.F., Patrick, K., Frank, L.D., Norman, G.J., 2009. Validation of the Neighborhood Environment Walkability Scale (NEWS) Items Using Geographic Information Systems. J. Phys. Act. Heal. 6, S113-S123. https://doi.org/10.1123/jpah.6.s1.s113

Agampodi, T.C., Agampodi, S.B., Glozier, N., Siribaddana, S., 2015. Measurement of social capital in relation to health in low and middle income countries (LMIC): A systematic review. Soc. Sci. Med. 128, 95-104. https://doi.org/10.1016/j.socscimed.2015.01.005

Austin, D.M., Furr, L.A., Spine, M., 2002. The effects of neighborhood conditions on perceptions of safety. J. Crim. Justice 30, 417-427. https://doi.org/10.1016/S00472352(02)00148-4

Baum, F.E., Palmer, C., 2002. "Opportunity structures": urban landscape, social capital and health promotion in Australia. Health Promot. Int. 17, 351-61.

Baum, F.E., Ziersch, A.M., Zhang, G., Osborne, K., 2009. Do perceived neighbourhood cohesion and safety contribute to neighbourhood differences in health? Health Place 15, 925-934. https://doi.org/10.1016/j.healthplace.2009.02.013

Bedney, B.J., Goldberg, R.B., Josephson, K., 2010. Aging in Place in Naturally Occurring Retirement Communities: Transforming Aging Through Supportive Service Programs. J. Hous. Elderly 24, 304-321. https://doi.org/10.1080/02763893.2010.522455

Berkman, L.F., Kawachi, I., 2000. Social epidemiology. Oxford University Press, New York, NY.

Bracy, N.L., Millstein, R. a, Carlson, J. a, Conway, T.L., Sallis, J.F., Saelens, B.E., Kerr, J., Cain, K.L., Frank, L.D., King, A.C., 2014. Is the relationship between the built environment and physical activity moderated by perceptions of crime and safety? Int. J. Behav. Nutr. Phys. Act. 11, 24. https://doi.org/10.1186/1479-5868-11-24

Brownson, R.C., Baker, E.A., Housemann, R.A., Brennan, L.K., Bacak, S.J., 2001. Environmental and Policy Determinants of Physical Activity in the United States. Am. J. Public Health 91, 1995-2003. https://doi.org/10.2105/AJPH.91.12.1995

Cerin, E., Conway, T.L., Saelens, B.E., Frank, L.D., Sallis, J.F., 2009. Cross-validation of the 
This paper was accepted by Social Science and Medicine. This is an author accepted version.

factorial structure of the Neighborhood Environment Walkability Scale (NEWS) and its abbreviated form (NEWS-A). Int. J. Behav. Nutr. Phys. Act. 6, 32. https://doi.org/10.1186/1479-5868-6-32

Cerin, E., Saelens, B.E., Sallis, J.F., Frank, L.D., 2006. Neighborhood Environment Walkability Scale: Validity and Development of a Short Form. Med. Sci. Sport. Exerc. 38, 1682-1691. https://doi.org/10.1249/01.mss.0000227639.83607.4d

Cho, J., Cook, C., Bruin, M.J., 2012. Functional Ability, Neighborhood Resources and Housing Satisfaction among Older Adults in the Functional Ability, Neighborhood Resources. J. Hous. Elderly 26, 395-412. https://doi.org/10.1080/02763893.2012.724376

Cho, Y., Park, G.-S., Echevarria-Cruz, S., 2005. Perceived neighborhood characteristics and the health of adult Koreans. Soc. Sci. Med. 60, 1285-1297. https://doi.org/10.1016/j.socscimed.2004.06.054

Clememte, F., Kleiman, M.B., 1976. Fear of Crime Among the Aged. Gerontologist 16, 207210. https://doi.org/10.1093/geront/16.3.207

Coley, R.L., Sullivan, W.C., Kuo, F.E., 1997. Where Does Community Grow?: The Social Context Created by Nature in Urban Public Housing. Environ. Behav. 29, 468-494. https://doi.org/10.1177/001391659702900402

Cramm, J.M., van Dijk, H.M., Nieboer, A.P., 2013. The Importance of Neighborhood Social Cohesion and Social Capital for the Well Being of Older Adults in the Community. Gerontologist 53, 142-152. https://doi.org/10.1093/geront/gns052

De Jesus, M., Puleo, E., Shelton, R.C., Emmons, K.M., 2010. Associations between perceived social environment and neighborhood safety: Health implications. Health Place 16, 100713. https://doi.org/10.1016/j.healthplace.2010.06.005

Forrest, R., Kearns, A., 2001. Social Cohesion, Social Capital and the Neighbourhood. Urban Stud. 38, 2125-2143. https://doi.org/10.1080/00420980120087081

Frank, L., Kerr, J., Chapman, J., Sallis, J., 2007. Urban Form Relationships with Walk Trip Frequency and Distance among Youth. Am. J. Heal. Promot. 21, 305-311. https://doi.org/10.4278/0890-1171-21.4s.305

Frank, L.D., Fox, E.H., Ulmer, J.M., Chapman, J.E., Kershaw, S.E., Sallis, J.F., Conway, T.L., Cerin, E., Cain, K.L., Adams, M.A., Smith, G.R., Hinckson, E., Mavoa, S., Christiansen, L.B., Hino, A.A.F., Lopes, A.A.S., Schipperijn, J., 2017. International comparison of observation-specific spatial buffers: maximizing the ability to estimate physical activity. Int. J. Health Geogr. 16, 4. https://doi.org/10.1186/s12942-017-0077-9

Frank, L.D., Kerr, J., Rosenberg, D., King, A.C., 2010a. Healthy Aging and Where You Live: Community Design Relationships With Physical Activity and Body Weight in Older Americans. J. Phys. Act. Health 7, S82-S90.

Frank, L.D., Sallis, J.F., Saelens, B.E., Leary, L., Cain, K., Conway, T.L., Hess, P.M., $2010 b$. The development of a walkability index: application to the Neighborhood Quality of Life Study. Br. J. Sports Med. 44, 924-933. https://doi.org/10.1136/bjsm.2009.058701

Frumkin, H., 2001. Beyond toxicity: Human health and the natural environment. Am. J. Prev. Med. 20, 234-240. https://doi.org/10.1016/S0749-3797(00)00317-2

Garrett, N., Schluter, P.J., Schofield, G., 2012. Physical Activity Profiles and Perceived Environmental Determinants in New Zealand: A National Cross-Sectional Study. J. Phys. Act. Heal. 9, 367-377. https://doi.org/10.1123/jpah.9.3.367

Gebel, K., Bauman, A.E., Sugiyama, T., Owen, N., 2011. Mismatch between perceived and objectively assessed neighborhood walkability attributes: prospective relationships with 
This paper was accepted by Social Science and Medicine. This is an author accepted version.

walking and weight gain. Health Place 17, 519-24. https://doi.org/10.1016/j.healthplace.2010.12.008

Giles-Corti, B., 2002. Socioeconomic Status Differences in Recreational Physical Activity Levels and Real and Perceived Access to a Supportive Physical Environment. Prev. Med. (Baltim). 35, 601-611. https://doi.org/10.1006/pmed.2002.1115

Giles-Corti, B., Broomhall, M.H., Knuiman, M., Collins, C., Douglas, K., Ng, K., Lange, A., Donovan, R.J., 2005. Increasing walking: How important is distance to, attractiveness, and size of public open space? Am. J. Prev. Med. 28, 169-176. https://doi.org/10.1016/j.amepre.2004.10.018

Glass, T.A., Balfour, J.L., 2003. Neighborhoods, aging, and functional limitations, in: Kawachi, I., Berkman, L.F. (Eds.), Neighborhoods and Health. Oxford University Press, New York, N.Y., pp. 303-334.

Gong, Y., Gallacher, J., Palmer, S., Fone, D., 2014. Neighbourhood green space, physical function and participation in physical activities among elderly men: the Caerphilly Prospective study. Int. J. Behav. Nutr. Phys. Act. 11, 40. https://doi.org/10.1186/1479-5868$11-40$

Groenewegen, P.P., van den Berg, A.E., de Vries, S., Verheij, R.A., 2006. Vitamin G: effects of green space on health, well-being, and social safety. BMC Public Health 6, 149. https://doi.org/10.1186/1471-2458-6-149

Groff, E., McCord, E.S., 2012. The role of neighborhood parks as crime generators. Secur. J. 25, 1-24. https://doi.org/10.1057/sj.2011.1

Hartig, T., Mitchell, R., de Vries, S., Frumkin, H., 2014. Nature and Health. Annu. Rev. Public Health 35, 207-228. https://doi.org/10.1146/annurev-publhealth-032013-182443

Jansson, M., Fors, H., Lindgren, T., Wiström, B., 2013. Perceived personal safety in relation to urban woodland vegetation - A review. Urban For. Urban Green. 12, 127-133. https://doi.org/10.1016/j.ufug.2013.01.005

Kawachi, I., Berkman, L.F., 2003. Neighbourhoods and health. Oxford University Press, New York, NY.

Kawachi, I., Kennedy, B.P., Glass, R., 1999. Social capital and self-rated health: a contextual analysis. Am. J. Public Health 89, 1187-1193. https://doi.org/10.2105/AJPH.89.8.1187

King, A.C., Castro, C., Wilcox, S., Eyler, A.A., Sallis, J.F., Brownson, R.C., 2000. Personal and environmental factors associated with physical inactivity among different racial-ethnic groups of U.S. middle-aged and older-aged women. Heal. Psychol. 19, 354-364. https://doi.org/10.1037/0278-6133.19.4.354

King, A.C., Sallis, J.F., Frank, L.D., Saelens, B.E., Cain, K., Conway, T.L., Chapman, J.E., Ahn, D.K., Kerr, J., 2011. Aging in neighborhoods differing in walkability and income: Associations with physical activity and obesity in older adults. Soc. Sci. Med. 73, 15251533. https://doi.org/10.1016/j.socscimed.2011.08.032

King, D., 2008. Neighborhood and Individual Factors in Activity in Older Adults: Results From the Neighborhood and Senior Health Study. J. Aging Phys. Act. 16, 144-170. https://doi.org/10.1123/japa.16.2.144

Kingsley, J. "Yotti", Townsend, M., 2006. "Dig In" to Social Capital: Community Gardens as Mechanisms for Growing Urban Social Connectedness. Urban Policy Res. 24, 525-537. https://doi.org/10.1080/08111140601035200

Kruger, D.J., Reischl, T.M., Gee, G.C., 2007. Neighborhood Social Conditions Mediate the Association Between Physical Deterioration and Mental Health. Am. J. Community 
This paper was accepted by Social Science and Medicine. This is an author accepted version.

473

474

475

476

477

478

479

480

481

482

483

484

485

486

487

488

489

490

491

492

493

494

495

496

497

498

499

500

501

502

503

504

505

506

507

508

509

510

511

512

513

514

515

516

517

518

Psychol. 40, 261-271. https://doi.org/10.1007/s10464-007-9139-7

Kweon, B.-S., Sullivan, W.C., Wiley, A.R., 1998. Green Common Spaces and the Social Integration of Inner-City Older Adults. Environ. Behav. 30, 832-858. https://doi.org/10.1177/001391659803000605

Lindquist, J.H., Duke, J.M., 1982. The Elderly Victim at Risk: Explaining the FearVictimization Paradox. Criminology 20, 115-126. https://doi.org/10.1111/j.17459125.1982.tb00451.x

Lovasi, G.S., Goh, C.E., Pearson, A.L., Breetzke, G., 2014. The independent associations of recorded crime and perceived safety with physical health in a nationally representative cross-sectional survey of men and women in New Zealand. BMJ Open 4, e004058. https://doi.org/10.1136/bmjopen-2013-004058

Lund, H., 2002. Pedestrian Environments and Sense of Community. J. Plan. Educ. Res. 21, 301312. https://doi.org/10.1177/0739456X0202100307

Maas, J., van Dillen, S.M.E., Verheij, R.A., Groenewegen, P.P., 2009a. Social contacts as a possible mechanism behind the relation between green space and health. Health Place 15, 586-595. https://doi.org/10.1016/j.healthplace.2008.09.006

Maas, J., Verheij, R.A., de Vries, S., Spreeuwenberg, P., Schellevis, F.G., Groenewegen, P.P., 2009b. Morbidity is related to a green living environment. J. Epidemiol. Community Health 63, 967-73. https://doi.org/10.1136/jech.2008.079038

Maruthaveeran, S., van den Bosh, C.K., 2015. Fear of crime in urban parks - What the residents of Kuala Lumpur have to say? Urban For. Urban Green. 14, 702-713. https://doi.org/10.1016/j.ufug.2015.05.012

Mendes de Leon, C.F., Cagney, K.A., Bienias, J.L., Barnes, L.L., Skarupski, K. a, Scherr, P.A., Evans, D.A., 2009. Neighborhood Social Cohesion and Disorder in Relation to Walking in Community-Dwelling Older Adults. J. Aging Health 21, 155-171. https://doi.org/10.1177/0898264308328650

Metz, D.., 2000. Mobility of older people and their quality of life. Transp. Policy 7, 149-152. https://doi.org/10.1016/S0967-070X(00)00004-4

Michael, Y.L., Green, M.K., Farquhar, S.A., 2006. Neighborhood design and active aging. Health Place 12, 734-740. https://doi.org/10.1016/j.healthplace.2005.08.002

Moore, S., Kawachi, I., 2017. Twenty years of social capital and health research: a glossary. J. Epidemiol. Community Health 71, 513-517. https://doi.org/10.1136/jech-2016-208313

Mowen, A., Orsega-Smith, E., Payne, L., Ainsworth, B., Godbey, G., 2007. The role of park proximity and social support in shaping park visitation, physical activity, and perceived health among older adults. J. Phys. Act. Health 4, 167-79.

Nasar, J.L., Fisher, B., Grannis, M., 1993. Proximate physical cues to fear of crime. Landsc. Urban Plan. 26, 161-178. https://doi.org/10.1016/0169-2046(93)90014-5

Parker, E.A., Lichtenstein, R.L., Schulz, A.J., Israel, B.A., Schork, M.A., Steinman, K.J., James, S.A., 2001. Disentangling Measures of Individual Perceptions of Community Social Dynamics: Results of a Community Survey. Heal. Educ. Behav. 28, 462-486. https://doi.org/10.1177/109019810102800407

Pollack, C.E., von dem Knesebeck, O., 2004. Social capital and health among the aged: comparisons between the United States and Germany. Health Place 10, 383-391. https://doi.org/10.1016/j.healthplace.2004.08.008

R Development Core Team, 2014. A language and environment for statistical computing.

Ruijsbroek, A., Droomers, M., Hardyns, W., Groenewegen, P.P., Stronks, K., 2016. The 
This paper was accepted by Social Science and Medicine. This is an author accepted version.

interplay between neighbourhood characteristics: The health impact of changes in social cohesion, disorder and unsafety feelings. Heal. Place 39, 1-8. https://doi.org/10.1016/j.healthplace.2016.02.001

Saelens, B.E., Sallis, J.F., Black, J.B., Chen, D., 2003. Neighborhood-based differences in physical activity: an environment scale evaluation. Am. J. Public Health 93, 1552-8.

Sallis, J.F., Johnson, M.F., Calfas, K.J., Caparosa, S., Nichols, J.F., 1997. Assessing Perceived Physical Environmental Variables that May Influence Physical Activity. Res. Q. Exerc. Sport 68, 345-351. https://doi.org/10.1080/02701367.1997.10608015

Sallis, J.F., Saelens, B.E., Frank, L.D., Conway, T.L., Slymen, D.J., Cain, K.L., Chapman, J.E., Kerr, J., 2009. Neighborhood built environment and income: examining multiple health outcomes. Soc. Sci. Med. 68, 1285-93. https://doi.org/10.1016/j.socscimed.2009.01.017

Sampson, R.J., 2003. Neighborhood-level context and health: Lessons from sociology, in: Kawachi, I., Berkman, L.F. (Eds.), Neighborhoods and Health. Oxford University Press, New York, N.Y., pp. 132-146. https://doi.org/10.1093/acprof:oso/9780195138382.003.0006

Sampson, R.J., Raudenbush, S.W., Earls, F., 1997. Neighborhoods and violent crime: A multilevel study of collective efficacy. Science (80-. ). 277, 918-24. https://doi.org/10.1126/science.277.5328.918

Seaman, P.J., Jones, R., Ellaway, A., 2010. It's not just about the park, it's about integration too: why people choose to use or not use urban greenspaces. Int. J. Behav. Nutr. Phys. Act. 7, 78. https://doi.org/10.1186/1479-5868-7-78

Shaffer, G.S., Anderson, L.M., 1985. Perceptions of the security and attractiveness of urban parking lots. J. Environ. Psychol. 5, 311-323. https://doi.org/10.1016/S02724944(85)80001-3

Sirven, N., Debrand, T., 2008. Social participation and healthy ageing: An international comparison using SHARE data. Soc. Sci. Med. 67, 2017-2026. https://doi.org/10.1016/j.socscimed.2008.09.056

Sugiyama, T., Leslie, E., Giles-Corti, B., Owen, N., 2008. Associations of neighbourhood greenness with physical and mental health: do walking, social coherence and local social interaction explain the relationships? J. Epidemiol. Community Health 62, e9. https://doi.org/10.1136/jech.2007.064287

Sullivan, W.C., Kuo, F.E., Depooter, S.F., 2004. The Fruit of Urban Nature. Environ. Behav. 36, 678-700. https://doi.org/10.1177/0193841X04264945

Tower, S.M., Groff, E., 2016. Examining the disorder-crime connection in Philadelphia parks. Secur. J. 29, 520-537. https://doi.org/10.1057/sj.2014.1

Troped, P.J., Saunders, R.P., Pate, R.R., Reininger, B., Addy, C.L., 2003. Correlates of recreational and transportation physical activity among adults in a New England community. Prev. Med. (Baltim). 37, 304-310. https://doi.org/10.1016/S00917435(03)00137-3

Troy, A., Morgan Grove, J., O’Neil-Dunne, J., 2012. The relationship between tree canopy and crime rates across an urban-rural gradient in the greater Baltimore region. Landsc. Urban Plan. 106, 262-270. https://doi.org/10.1016/j.landurbplan.2012.03.010

Van Dijk, H.M., Cramm, J.M., Nieboer, A.P., 2014. Social cohesion as perceived by communitydwelling older people: the role of individual and neighbourhood characteristics. Int. J. Ageing Later Life 8, 9-31. https://doi.org/10.3384/ijal.1652-8670.13210

Weiss, C.C., Purciel, M., Bader, M., Quinn, J.W., Lovasi, G., Neckerman, K.M., Rundle, A.G., 
This paper was accepted by Social Science and Medicine. This is an author accepted version.

2011. Reconsidering Access: Park Facilities and Neighborhood Disamenities in New York City. J. Urban Heal. 88, 297-310. https://doi.org/10.1007/s11524-011-9551-z

Wolfe, M.K., Mennis, J., 2012. Does vegetation encourage or suppress urban crime? Evidence from Philadelphia, PA. Landsc. Urban Plan. 108, 112-122. https://doi.org/10.1016/j.landurbplan.2012.08.006

Wood, L., Shannon, T., Bulsara, M., Pikora, T., McCormack, G., Giles-Corti, B., 2008. The anatomy of the safe and social suburb: An exploratory study of the built environment, social capital and residents' perceptions of safety. Health Place 14, 15-31. https://doi.org/10.1016/j.healthplace.2007.04.004

Yen, I.H., Michael, Y.L., Perdue, L., 2009. Neighborhood Environment in Studies of Health of Older Adults. Am. J. Prev. Med. 37, 455-463. https://doi.org/10.1016/j.amepre.2009.06.022 Young, A.F., Russell, A., Powers, J.R., 2004. The sense of belonging to a neighbourhood: can it be measured and is it related to health and well being in older women? Soc. Sci. Med. 59, 2627-2637. https://doi.org/10.1016/j.socscimed.2004.05.001

Ziersch, A.M., Baum, F.E., Macdougall, C., Putland, C., 2005. Neighbourhood life and social capital: the implications for health. Soc. Sci. Med. 60, 71-86. https://doi.org/10.1016/j.socscimed.2004.04.027 
This paper was accepted by Social Science and Medicine. This is an author accepted version.

Table 1. Descriptive Summary of Participant Characteristics ( $n=647$, Seattle-King County \& Baltimore-Washington DC region)

\begin{tabular}{|c|c|c|}
\hline Variables & Mean (SD) or N (\%) & Range \\
\hline \multicolumn{3}{|l|}{ Sociodemographics } \\
\hline Age & $74.18(6.19)$ & $66-97$ \\
\hline Female (\%) & $335(51.8)$ & \\
\hline \multicolumn{3}{|l|}{ Education (\%) } \\
\hline sHigh school & $138(21.3)$ & \\
\hline Some college & $191(29.5)$ & \\
\hline College degree & $168(26.0)$ & \\
\hline$\geq$ Graduate school & $150(23.2)$ & \\
\hline \multicolumn{3}{|l|}{ Household income (\%) } \\
\hline$<\$ 20,000$ & $102(17.0)$ & \\
\hline$\$ 20,000-39,000$ & $178(29.7)$ & \\
\hline$\$ 40,000-69,000$ & $160(26.7)$ & \\
\hline$\geq \$ 70,000$ & $159(26.5)$ & \\
\hline Missing & $48(7.4)$ & \\
\hline Married/living with partner ${ }^{\ddagger}(\%)$ & $456(70.7)$ & \\
\hline White (\%) & $548(85.0)$ & \\
\hline \multicolumn{3}{|l|}{ Home- and health-related factors } \\
\hline Homeowner ${ }^{\ddagger}(\%)$ & $548(85.0)$ & \\
\hline Years of residence $^{+}$ & $25.05(15.43)$ & $1-74$ \\
\hline General health & $3.47(0.91)$ & $1-5$ \\
\hline \multicolumn{3}{|l|}{ Green space } \\
\hline Distance (meters) to nearest park & $823.66(602.67)$ & \\
\hline Natural sights & $2.93(0.92)$ & $1-4$ \\
\hline Street trees & $3.44(0.80)$ & $1-4$ \\
\hline \multicolumn{3}{|l|}{ Perceived safety } \\
\hline Traffic safety & $2.73(0.69)$ & $1-4$ \\
\hline Pedestrian safety & $2.65(0.45)$ & $1-4$ \\
\hline Personal safety & $3.40(0.61)$ & $1-4$ \\
\hline \multicolumn{3}{|l|}{ Neighborhood social capital } \\
\hline Social cohesion $n^{\ddagger}$ & $3.73(0.74)$ & $1-5$ \\
\hline Social interaction ${ }^{\ddagger}$ & $13.08(8.82)$ & $1-30$ \\
\hline
\end{tabular}

${ }^{\dagger} 1$ missing data, ${ }^{\ddagger} 2$ missing data 
Table 2. Relationships between green space, perceived safety, and social cohesion

\begin{tabular}{|c|c|c|c|c|c|}
\hline \multirow{3}{*}{ Variables } & \multicolumn{5}{|c|}{ Dependent Variable: Social Cohesion $(N=647)^{\dagger}$} \\
\hline & Model 1 & Model 2 & Model 3 & Model 4 & Model 5 \\
\hline & $\mathrm{B}(\mathrm{SE})$ & $\mathrm{B}(\mathrm{SE})$ & $\mathrm{B}(\mathrm{SE})$ & $\mathrm{B}(\mathrm{SE})$ & $\mathrm{B}(\mathrm{SE})$ \\
\hline Intercept & $3.707 * * *(0.035)$ & $3.292 * * *(0.405)$ & $3.256 * * *(0.405)$ & $3.333 * * *(0.406)$ & $3.228 * * *(0.407)$ \\
\hline Site (1=Baltimore/Washington DC) & & $-0.031(0.060)$ & $-0.028(0.059)$ & $-0.026(0.060)$ & $-0.025(0.059)$ \\
\hline \multicolumn{6}{|l|}{ Green space } \\
\hline Distance $(\mathrm{m})$ to nearest park & & $-0.00004(0.00005)$ & $-0.00003(0.00005)$ & $-0.00005(0.00005)$ & $-0.00004(0.00005)$ \\
\hline Natural sights & & $0.128 * * *(0.034)$ & $0.129 * * *(0.034)$ & $0.127 * * *(0.034)$ & $0.130 * * *(0.034)$ \\
\hline Street trees & & $0.016(0.036)$ & $0.035(0.037)$ & $0.033(0.037)$ & $0.044(0.038)$ \\
\hline \multicolumn{6}{|l|}{ Perceived safety } \\
\hline Traffic safety & & $0.036(0.046)$ & $0.033(0.046)$ & $0.033(0.046)$ & $0.025(0.046)$ \\
\hline Pedestrian safety & & $0.221 * * *(0.067)$ & $0.217 * * *(0.068)$ & $0.217 * * *(0.067)$ & $0.223 * * *(0.068)$ \\
\hline Personal safety & & $0.242 * * *(0.051)$ & $0.249 * * *(0.051)$ & $0.248 * * *(0.052)$ & $0.259 * * *(0.053)$ \\
\hline \multicolumn{6}{|l|}{ Interactions } \\
\hline Traffic safety x Distance to park & & $-0.00001(0.0001)$ & & & $0.00002(0.0001)$ \\
\hline Traffic safety $x$ Natural sights & & $-0.027(0.043)$ & & & $0.022(0.051)$ \\
\hline Traffic safety x Street trees & & $-0.046(0.053)$ & & & $-0.105(0.057)$ \\
\hline Pedestrian safety $\mathrm{x}$ Distance to park & & & $-0.0001(0.0001)$ & & $-0.0001(0.0001)$ \\
\hline Pedestrian safety $x$ Natural sights & & & $-0.107(0.069)$ & & $-0.108(0.080)$ \\
\hline Pedestrian safety $x$ Street trees & & & $0.168 *(0.086)$ & & $0.185^{* *}(0.056)$ \\
\hline Personal safety $\mathrm{x}$ Distance to park & & & & $-0.00004(0.0001)$ & $-0.00004(0.0001)$ \\
\hline Personal safety x Natural sights & & & & $-0.070(0.048)$ & $-0.052(0.052)$ \\
\hline Personal safety $\times$ Street trees & & & & $0.078(0.049)$ & $0.070(0.053)$ \\
\hline \multicolumn{6}{|l|}{ Random Effect } \\
\hline No. of Block Group & 209 & 209 & 209 & 209 & 209 \\
\hline Block Group Variance & 0.077 & 0.014 & 0.009 & 0.012 & 0.009 \\
\hline $\mathrm{N}$ & 645 & 640 & 640 & 640 & 640 \\
\hline Log Likelihood & -713.701 & -642.295 & -640.360 & -641.080 & -637.678 \\
\hline AIC & 1433.402 & 1338.590 & 1334.720 & 1336.159 & 1341.357 \\
\hline $\mathrm{BIC}$ & 1446.810 & 1459.050 & 1455.180 & 1456.619 & 1488.585 \\
\hline
\end{tabular}


Table 3. Relationships between green space, perceived safety, and social interaction

\begin{tabular}{|c|c|c|c|c|c|}
\hline \multirow{3}{*}{ Variables } & \multicolumn{5}{|c|}{ Dependent Variable: Social Interaction $(N=647)^{\dagger}$} \\
\hline & Model 1 & Model 2 & Model 3 & Model 4 & Model 5 \\
\hline & B (SE) & $B(S E)$ & $\mathrm{B}(\mathrm{SE})$ & B (SE) & $B(S E)$ \\
\hline Intercept & $13.008 * * *(0.403)$ & $21.079 * * *(5.050)$ & $20.612^{* * *}(5.077)$ & $22.372^{* * *}(5.088)$ & $20.925^{* * *}(5.073)$ \\
\hline Site (1=Baltimore/Washington DC) & & $1.833^{* *}(0.812)$ & $1.860 * *(0.805)$ & $1.713^{* *}(0.814)$ & $1.491 *(0.804)$ \\
\hline \multicolumn{6}{|l|}{ Green space } \\
\hline Distance $(m)$ to nearest park & & $-0.001(0.001)$ & $-0.001(0.001)$ & $-0.001(0.001)$ & $-0.001(0.001)$ \\
\hline Natural sights & & $1.160 * * *(0.424)$ & $1.183^{* * *}(0.427)$ & $1.166^{* * *}(0.423)$ & $1.234 * * *(0.424)$ \\
\hline Street trees & & $0.712(0.455)$ & $0.664(0.471)$ & $0.789 *(0.469)$ & $0.772 *(0.474)$ \\
\hline \multicolumn{6}{|l|}{ Perceived safety } \\
\hline Traffic safety & & $-1.004 *(0.576)$ & $-0.927(0.576)$ & $-0.908(0.580)$ & $-1.016 *(0.576)$ \\
\hline Pedestrian safety & & $2.188^{* *}(0.850)$ & $2.171 * *(0.857)$ & $2.024 * *(0.852)$ & $2.200 * * *(0.853)$ \\
\hline Personal safety & & $-0.918(0.637)$ & $-0.912(0.642)$ & $-0.930(0.664)$ & $-0.816(0.661)$ \\
\hline \multicolumn{6}{|l|}{ Interactions } \\
\hline Traffic safety $x$ Distance to park & & $-0.001(0.001)$ & & & $-0.001(0.001)$ \\
\hline Traffic safety $\times$ Natural sights & & $-0.135(0.541)$ & & & $-0.256(0.637)$ \\
\hline Traffic safety $x$ Street trees & & $-1.090(0.660)$ & & & $-1.128(0.712)$ \\
\hline Pedestrian safety $\times$ Distance to park & & & $-0.003 * *(0.001)$ & & $-0.003 * *(0.001)$ \\
\hline Pedestrian safety $\times$ Natural sights & & & $-0.403(0.865)$ & & $-0.108(0.994)$ \\
\hline Pedestrian safety $\times$ Street trees & & & $-0.470(1.078)$ & & $-0.571(1.202)$ \\
\hline Personal safety $\mathrm{x}$ Distance to park & & & & $0.001(0.001)$ & $0.002(0.001)$ \\
\hline Personal safety x Natural sights & & & & $-0.006(0.605)$ & $0.062(0.650)$ \\
\hline Personal safety $\times$ Street trees & & & & $0.266(0.610)$ & $0.895(0.660)$ \\
\hline \multicolumn{6}{|l|}{ Random Effect } \\
\hline No. of Block Group & 209 & 209 & 209 & 209 & 209 \\
\hline Block Group Variance & 7.515 & 5.991 & 5.489 & 5.552 & 5.145 \\
\hline $\mathrm{N}$ & 645 & 640 & 640 & 640 & 640 \\
\hline Log Likelihood & -2313.565 & -2259.742 & -2260.104 & -2261.535 & -2254.341 \\
\hline AIC & 4633.129 & 4573.483 & 4574.207 & 4577.07 & 4574.682 \\
\hline BIC & 4646.537 & 4693.943 & 4694.667 & 4697.53 & 4721.911 \\
\hline
\end{tabular}

Note: ${ }^{\dagger}$ Of the 647 samples, there are 7 missing data ( 2 missing the outcome measures; 2 missing marital status; 2 missing home ownership; and 1 missing years of residence). A dummy was created to handle 48 missing income data. All models are adjusted for age, sex, marital status, race, income, education, home ownership, years of residence, and general health status.

Significance levels: $* p<0.10, * * p<0.05, * * * p<0.01$ 
This paper was accepted by Social Science and Medicine. This is an author accepted version.
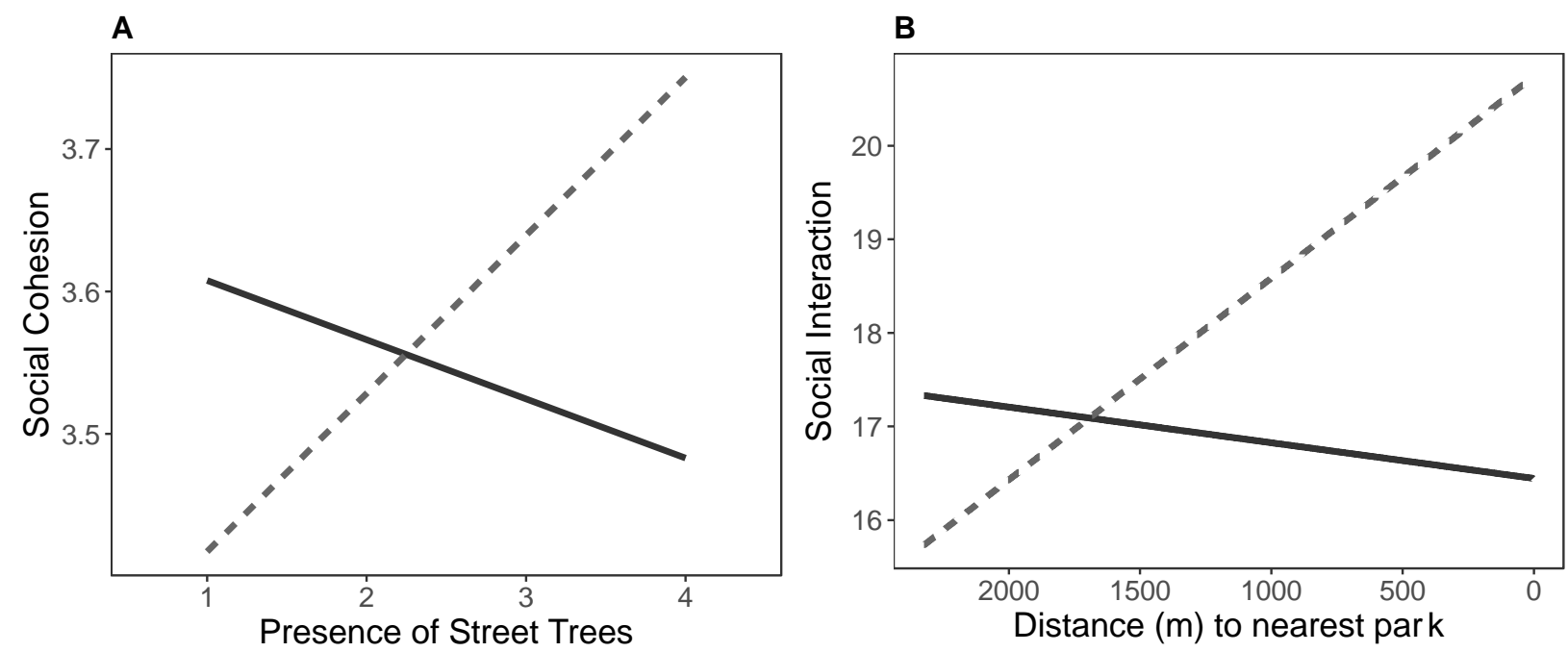

Pedestrian Safety — Low = - High

Figure 1. Interaction of pedestrian safety with street trees in relation to social cohesion (a); and with park access in relation to social interaction (b)

Note: The interaction effects were plotted by holding covariates constant at their mean values. Presence of street trees ranked from 1 (strongly disagree) to 4 (strongly agree). For pedestrian safety, "Low" and "High" refer to values 1 standard deviation below and above the mean. 